Proceedings of the 2011 Winter Simulation Conference

S. Jain, R.R. Creasey, J. Himmelspach, K.P. White, and M. Fu, eds.

\title{
ENVIRONMENTAL ACTIVITY BASED COST USING DISCRETE EVENT SIMULATION
}

\author{
Jon Andersson \\ Anders Skoogh \\ Björn Johansson \\ Chalmers University of Technology \\ Product and Production Development \\ SE-41296 Gothenburg, SWEDEN
}

\begin{abstract}
Discrete event simulation (DES) provides engineers with a flexible modeling capability for extensive analysis of a production flow and its dynamic behavior. Activity based costing (ABC) modeling can provide additional knowledge about the monetary costs related to the manufacturing processes in DES. In addition, $\mathrm{ABC}$ modeling has been proposed as a tool for environmental impact analysis. Thus, previous studies have separately brought $\mathrm{ABC}$ into DES and $\mathrm{ABC}$ into environmental impact analysis. Bringing all three areas together, an $\mathrm{ABC}$ environmental simulation could provide deeper understanding about environmental impacts in the manufacturing processes than a regular Life Cycle Assessment (LCA) analysis. This paper proposes to use $\mathrm{ABC}$ modeling in conjunction with DES to perform a more detailed economic and environmental impact cost analysis. It is emphasized that the time to perform both analysis in one simulation is shorter or equal to perform them separately. Moreover, the approach can resolve some LCA problems.
\end{abstract}

\section{INTRODUCTION}

Discrete event simulation (DES) is a powerful tool for analyzing and evaluating production flows without affecting the production. DES is mainly used for evaluating process improvements and justifying investment decisions. However, only few companies use DES technology on a regular basis (Ericsson 2005). To enable pervasive and wider use of DES by companies on a daily basis, DES tools should be made more user friendly, more analytical and provide decision support. Extensions and improvements of the usability in simulation models would greatly benefit DES as an analysis tool, and thus, making it more worthwhile to use.

This paper reviews how $\mathrm{ABC}$ can be used to allocate of environmental impact costs to batches or units of products. It deliberates on the opportunities of using the $\mathrm{ABC}$ approach in a DES environment to investigate the environmental and economic costs of a production system. The paper examines two approaches/methods; $\mathrm{ABC}$ calculations combined with DES and $\mathrm{ABC}$ calculations with environmental impact analysis. It elaborates the benefits of the synergistic effect of the combined approach and the problems associated with the method. It concludes with a discussion on the criteria used to evaluate the approach described.

\subsection{Background}

There is an increased need to analyze and present environmental impact of manufactured products. This need is driven by government regulations as well as by consumer's interests. Several studies have shown that environmental labeling of a product provides a positive and competitive advantage for companies if the work is communicated to customers (Gallego-Álvarez et al. 2010; Russo and Fouts 1997). Products 
that come with a declaration of environmental impact have a competitive advantage over those without even though the product without the declaration might be more environmental friendly. A recent study by MIT Sloan (Haanaes et al. 2011) has shown that more than $90 \%$ of manufacturing companies in a wide range of industries believe that pursuing sustainability is necessary to be competitive.

It does most often take much time and effort to build a sound DES model that accurately mimics the behavior of a production system. Once such a model is developed, it is important to use it for as many beneficial purposes as possible. Very often, environmental impact analysis is based on static methods such as Life Cycle Assessment (LCA), which is a common and standardized method (ISO 140040 and ISO14044) (European Commission 2010). A static model lacks the capabilities to analyze a system's dynamic behaviors, e.g., economic and environmental impacts of machine operations, breakdowns, and variations in cycle times. It is difficult to estimate the impact of dynamic changes to a complex production environment using such a static model. Dynamic models, on the other hand, provide deeper understanding of complex production systems and determine the sources of the environmental impact. If the environmental impact analysis is performed, using a DES model, accuracy can be improved and less rework is required for future LCA analyses. A DES model can be used as a sandbox system to run experiments to evaluate, not only the efficiency, but also the environmental impact and the real economic costs of production.

A study made by Thiede, Herrmann and Kara (2011) analyzed the current state of art in using DES to study a multi-machine production system with environmental issues. The researchers explored twelve approaches; the main is the material flow approach. It analyzed sustainability factors of the machines in the production system. The inputs are energy and raw material while the outputs are the product, carbon dioxide emissions, toxic materials, and waste.

Previous papers studied the possibilities of combining ABC calculations together with DES models (Beck and Nowak 2000). It has been shown that ABC can be used in a DES environment to analyze costs. Besides economical costs, environmental impacts can be analyzed as costs as well (Emblemsvåg 2001). These studies have investigated the advantages of performing environmental impact analyzes using ABC calculations.

\subsection{Objective}

The objective of this paper's research is to evaluate the feasibility of performing environmental impact analysis with DES models using the ABC framework. It discusses a method to analyze the environmental impact of a product using $\mathrm{ABC}$ calculation in combination with DES models. This is the first paper for the project called EcoProIT (2011). EcoProIT aims at develop a tool, which can be used by industry for evaluating and marking product environmental footprints throughout the product's lifecycle. This paper evaluates a combination of existing methods to use for the environmental calculations in the tool.

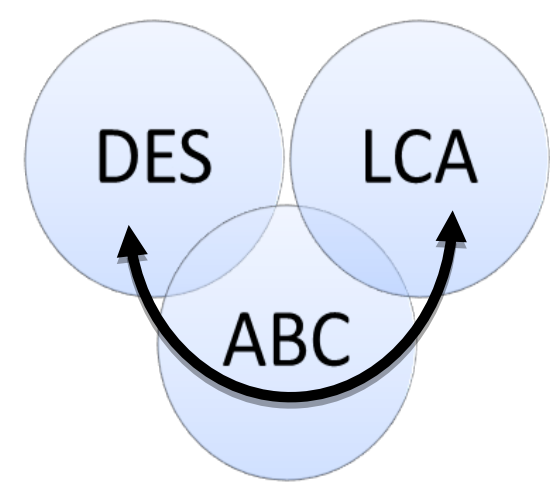

Figure 1: LCA and DES are linked with $\mathrm{ABC}$ as a bridge 


\subsection{Criteria for Approach Evaluation}

The criterion for evaluation compares if there are any advantages of using $\mathrm{ABC}$ in DES for environmental impact analysis over a static LCA analysis. In the literature review and the case example, the criterions is used to evaluate if the solution is better than LCA or not. The criteria are defined to achieve a fruitful and better use of both LCA and DES in combination rather than using the two methods on their own. The following criteria are used:

1. It should be cheaper or less time consuming to use the proposed approach compared using both DES and LCA separately.

2. Related problems to the separated approaches $\mathrm{ABC}$ in a DES environment and environmental impact analysis in $\mathrm{ABC}$ models should be reduced or be equally extensive.

3. The environmental impact analysis should be less or as dependent on the analyst as using an LCA analysis by itself.

4. The approach should be able to provide equal or more information compared to using DES and LCA separately.

\section{ACTIVITY BASED COST IN DISCRETE EVENT SIMULATION}

$\mathrm{ABC}$ calculation is a well-known method for analyzing, allocating, and distributing costs for operations to products or services. The method is able to reveal the real production cost for the products, and traces costs more easily to their origins. $\mathrm{ABC}$ accounting is more adaptive and a better representation of the real costs in production and organization compared to traditional cost accounting. However, it is extremely time consuming and costly to perform a detailed $\mathrm{ABC}$ calculation because there are simply too many products and activities combinations of manufacturing operations on the shop floor (Spedding and Sun 1999).

Despite of the benefits, the adoption rate of $\mathrm{ABC}$ among companies is as low as around 10-30\% depending on the size, location, and type of company (Cohen, Venieris, and Kaimenaki 2005).
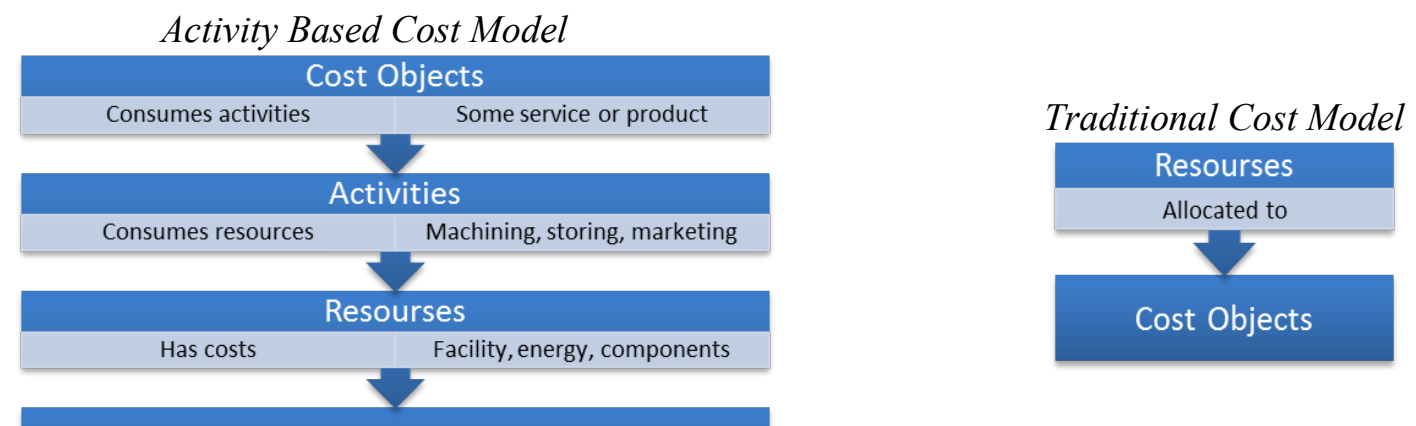

Economical costs (and environmental impact)

Figure 2: A conceptual ABC model and a traditional cost model

The multitude of problems encountered while designing an efficient ABC model makes good support software essential and necessary. Beck and Nowak (2000) investigated how to merge DES with ABC calculation. Their studies shown that an ABC calculation fits properly and can be implemented with minimum effort into an existing DES model. The ABC calculation adds a deeper understanding to the original sources of cost and help engineers find low-profit products in a multi-product manufacturing environment. Moreover, in Spedding and Sun's (1999) investigation, it was concluded that DES could help solve some of the issues in allocating and distributing overhead cost to resources with ABC. When drivers (weight, volume, area) for costs are defined, it is possible to use DES model to allocate fixed overhead 


\section{Andersson, Skoogh, and Johansson}

costs down to individual batch or unit of product. Nevertheless, there will always be decision problems in coping with allocation of overhead costs. For example, allocation of the heating cost for product produced at the production site could be computed by accumulating the amount of time a batch of product spent at the site and by the area for which a produced batch is occupying or stored. The model will track the total areas for all the batches at the site and distribute e.g. heating costs accordingly among the batches of products.

\subsection{ABC Implemented using DES}

There are multiple methods available for designing an $\mathrm{ABC}$ model. Important steps on how to perform the ABC design is described by Gunasekaran (1999). Figure 3 shows a schematic image of such an ABC design.

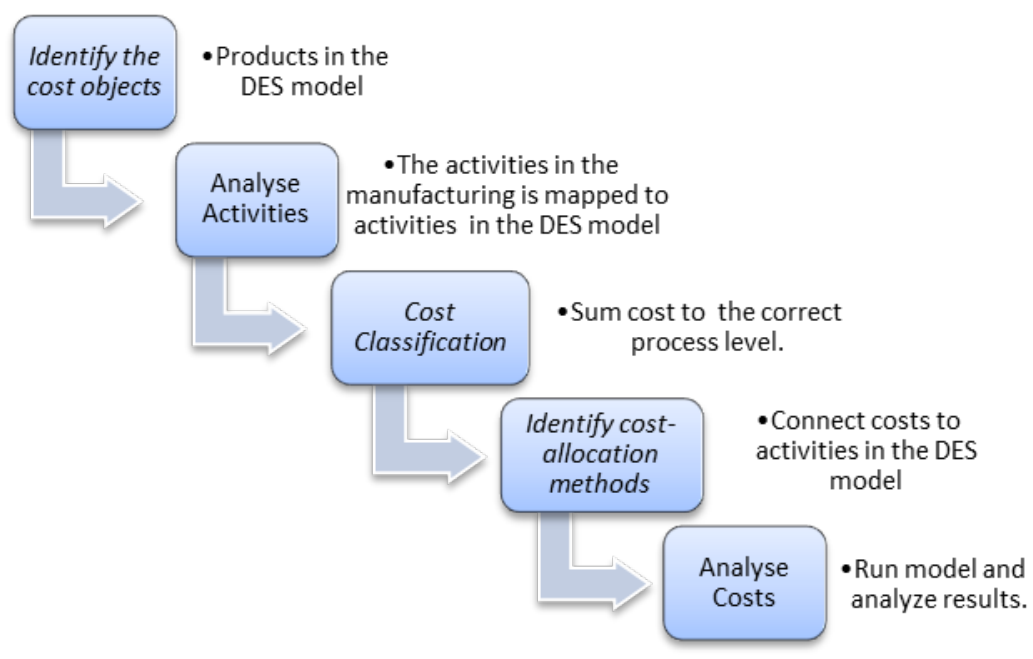

Figure 3: Five generic steps in $\mathrm{ABC}$ calculations

Identify the cost objects is an inventory on the products/services that carry costs in the organization. In a manufacturing environment, it is often a matter of end products and major premade parts. The cost objects are represented in the DES models as products produced in the simulation.

Analyze the activities is an enumeration of the activities performed to the cost objects. The cost for the cost object in activities is all driven by a "cost-driver" in a manufacturing environment. Examples of cost drivers are weight, size, and time, or combination of weight multiplied by transportation distance. The connection of activities in a DES model will be direct without any big implementation difficulties.

Cost Classification. There are a couple of levels where costs for a product can originate. Costs then allocate from a high level down to a lower level depending on activities by a lower level, or equally as a static cost. For example, facility costs can be allocated to the batch level or unit product level directly depending on the actual area usage of the batches at the facility.

- Unit level, each time a cost object uses an activity, e.g. processed in a machine.

- Batch level, each time a batch use an activity, e.g. store in temporary storage.

- Product level, supporting activities for all of the products, e.g. product marketing.

- Facility level, overhead cost for the facility where the unit currently is.

In a DES model, this allocation is a direct implementation step. The location for the product in the model is a direct base for collection of different costs in multiple layers and activities. The costs can then be allocated down or summed up in the level hierarchy to analyze costs at different levels. 
Identify cost allocation methods is to connect costs to activities. It is especially important to establish a method to allocate overhead costs that apply to the facility level. Analyzes on how overhead costs should be applied to either the individual unit or product is vital for a good $\mathrm{ABC}$ analyze.

Analyzes of the cost result is a key strength of $\mathrm{ABC}$ modeling. In $\mathrm{ABC}$, it is possible to track down the origins or sources of the costs. The DES approach would add extra dimensions and features to analyze the cost of activities in more detail. The DES model could show if there are major variations in costs for individual products and analyze the robustness of the system (Gunasekaran 1999).

\section{ENVIRONMENTAL CALCULATIONS USING ACTIVITY BASED COST}

Emblemsvåg and Bras (2000) developed a method to include environmental impact analysis in $\mathrm{ABC}$ modeling. The method has been tested but it is rarely used in practice. Emblemsvåg and Bras (2000) stated five purposes to use their method instead of the standardized LCA (ISO 14041 and ISO 14044) method (European Commission 2010). The purposes are:

- Their method yields results that are simpler to compare, which should eliminate one of the biggest criticisms against LCA.

- The method is able to analyze costs and environmental effects at the same time based on wellproven techniques from $\mathrm{ABC}$ method.

- $\mathrm{ABC}$ is the only approach that has been demonstrated to handle overhead costs in a credible way.

- LCA focuses on one product at a time, whereas ABC as able to address all products at the same time. Focusing on only one product could miss economy-of-scale effects, which in turn could lead to wrong conclusions. (Emblemsvåg and Bras 2000)

- The approach takes advantage of well-proven experiences and matured $\mathrm{ABC}$ techniques.

Studies have been performed analyzing the best practice on how to decide on the allocation of climate cost to individual units. One of the most common questions asked while designing the driver is, "what has to be done to produce the product type that are increasing the total environmental impacts for the plant, and how is it increasing"? The complexity of allocating overhead costs is discussed in Emblemsvåg and Bras (1999). A product that carries a bigger portion of overhead costs will lead to a lower overhead costs for other products. For example, after a change in production flow, product $A$ has to increase the time it spends in the storage. Product $A$ will have to carry more of the overhead costs from heating and administration. Then Product $B$ and $C$ will carry less overhead costs, which translates to a lower environmental impact. Moreover, Emblemsvåg and Bras (1999) presented a schematic method for designing an activitybased LCA model. The original method included energy consumption and a waste index. The waste index is out of scope for this paper. An activity-based LCA design is presented in Figure 4 and it is in general terms similar to the $\mathrm{ABC}$ method.

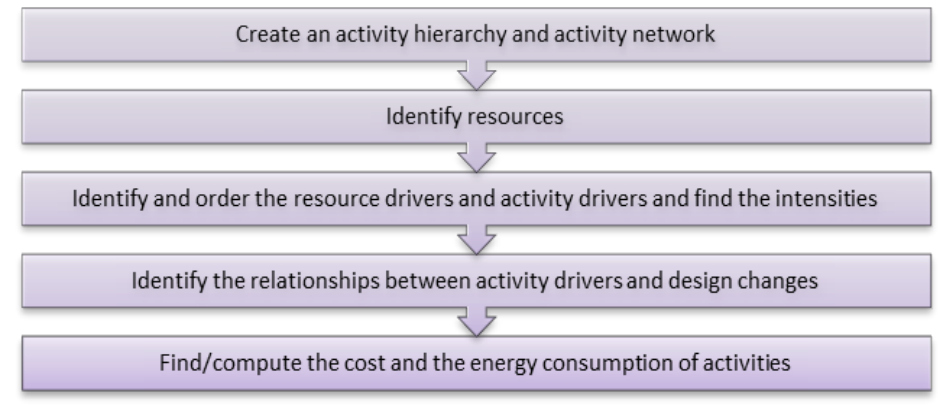

Figure 4: Major parts of activity-based LCA design model by Emblemsvåg and Bras (1999) 


\subsection{Allocation of Environmental Impact Costs using ABC}

To perform a robust environmental impact analysis, many different factors must be considered. The scope and purpose of the analysis defines the needed input and output. In an environmental footprint analysis, any undefined number of outputs can be evaluated. Because of continuous research, new environmental footprint measurements are considered. This paper examines and studies a few common impact categories such as carbon footprint, Global Warming Potential (GWP), and acidification. Studies have found that there are correlations on calculating environmental impacts and economics costs (Emblemsvåg 2001).

Costs can be categorized as direct and indirect costs. These categories can be mapped to environmental impact, i.e. direct environmental impact and indirect environmental impact. It is possible to connect direct environmental impacts to individual products while further definition and analysis are needed to account for indirect environmental impacts. Indirect environmental impacts are those that originate from supporting resources such as facility, support organizations, and maintenance or repairs. It correlates well also to economic $\mathrm{ABC}$ accounting.

Allocation of overhead (indirect) costs to a batch or unit of product is an important function in $\mathrm{ABC}$ modeling. It is a challenge when modeling an $\mathrm{ABC}$ calculation to distribute the indirect expenses such as administration, facility, and labor costs to the products. An important step is to decide on the drivers for different products' costs. The International Reference Life Cycle Data System (ILCD) Handbook (European Commission 2010) provides best practices in LCA projects for companies. The handbook describes, among other things, allocation policies for costs in a multifunctional environment and provides example on allocation problems for several common overhead costs. The document can serve as the framework for allocating overhead costs. Many of the indirect costs are allocated preferable with time as an impact driver. Hence, a DES environment could support implementation of these recommendations from the handbook. Table 1 shows common costs and how it is coupled to a DES environment as well as the cost level. The cost level was introduced in section 2.1 and represents the associated level for the overhead costs. From the cost level, cost can be allocated to all the individual units for summation of unit level impact costs.

Table 1: Allocation examples in a production environment

\begin{tabular}{|c|c|c|c|}
\hline Costs & Cost level & Resource/cost driver & Solved in \\
\hline $\begin{array}{l}\text { Machine Energy } \\
\text { costs }\end{array}$ & Unit & Machine time an unit is manufactured. & $\begin{array}{l}\text { Actual machine time is } \\
\text { tracked in the model. }\end{array}$ \\
\hline $\begin{array}{l}\text { Auxiliary ma- } \\
\text { chine support }\end{array}$ & Unit & $\begin{array}{l}\text { Time an unit of product is machined. } \\
\text { Total cost for Auxiliary machine support } \\
\text { is shared by all units of products. }\end{array}$ & $\begin{array}{l}\text { Machine time is } \\
\text { tracked in the model. }\end{array}$ \\
\hline External transport & Unit/Batch & Time or distance and mass or volume. & Static cost \\
\hline Internal transport & Unit/Batch & Time and mass or volume. & $\begin{array}{l}\text { Transport is simulated } \\
\text { and time tracked. }\end{array}$ \\
\hline $\begin{array}{l}\text { Machine Mainte- } \\
\text { nance/ Set-up }\end{array}$ & Batch & $\begin{array}{l}\text { Equally allocated by time at the machine } \\
\text { during a production period, e.g. one day }\end{array}$ & $\begin{array}{l}\text { DES keeps track of } \\
\text { machined batches }\end{array}$ \\
\hline $\begin{array}{l}\text { Product Support- } \\
\text { ing Functions }\end{array}$ & Product & $\begin{array}{l}\text { Share of product value in turnover. From } \\
\text { product, the cost is allocated equally to } \\
\text { the number of products. }\end{array}$ & Static cost. \\
\hline $\begin{array}{l}\text { System Mainte- } \\
\text { nance }\end{array}$ & Product & $\begin{array}{l}\text { Depending on the amount of time the } \\
\text { system is used to support the product } \\
\text { type. The cost is allocated equally to the } \\
\text { number of products. }\end{array}$ & $\begin{array}{l}\text { DES model tracks the } \\
\text { system usage. }\end{array}$ \\
\hline Facility Costs & Facility & $\begin{array}{l}\text { Time and area the batch occupies the fa- } \\
\text { cility. For three-dimensional storages, } \\
\text { volume is used. }\end{array}$ & $\begin{array}{l}\text { DES tracks the time } \\
\text { and area the batch oc- } \\
\text { cupies the facility. }\end{array}$ \\
\hline
\end{tabular}




\section{DES ACTIVITY BASED ENVIRONMENTAL IMPACT ANALYSIS}

The link between environmental impact calculations and DES with the help of ABC is shown to be selfevident. Hence, the coupling between DES to $\mathrm{ABC}$ is possible and furthermore the environmental impact calculation to $\mathrm{ABC}$ correlates with the foundation of the $\mathrm{ABC}$ method.

Many of the problems of environmental impact calculations are consistent throughout all environmental impact estimation methods, e.g. quality environmental impact data is hard to get and hard to verify. However, there is no evidence that problems are increased while using the methods combined as of now.

Often times during the study, the analyst is compelled to make assumptions that may significantly influence the end result. To avoid conflicting end results, sensitivity analysis is important to mitigate the risks. In a dynamic model, sensitivity analysis is done preferably using a computer. In a DES-ABC approach, the DES-tool can easily implement such a feature. As long as the products are continuously processed through the production line, environmental costs are captured and added to the product. Instead of summing the costs directly, it is possible to include additional terms to an impact function. In Figure 5, the individual impact terms are functions that results in a vector of environmental costs.

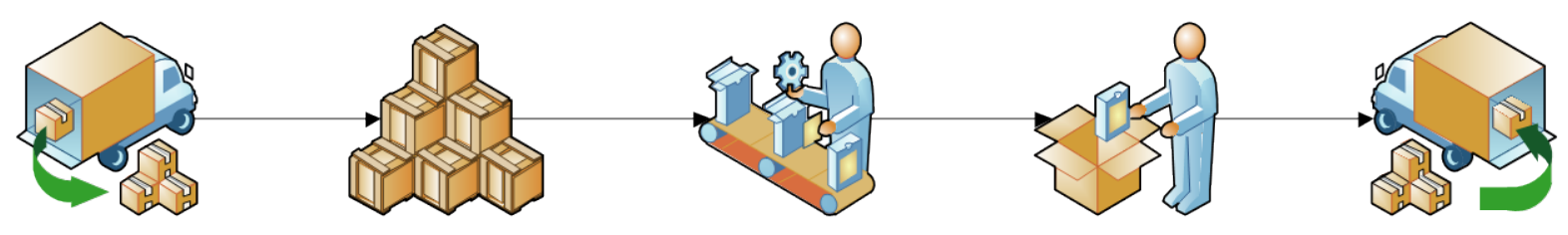

Figure 5: An example of a simple production line to exemplify activities in production.

Environmental impact costs are added as terms to an impact function:

Environmental impact costs $=$ Raw material costs + Transport costs + assembled parts costs + assembly costs + packaging costs + overhead costs for time in factory + delivery costs

The cost vector for the Assembly station could be a function as:

\section{Global warm up effect $=$ Machine impact per time $\times$ machine time + added material effect Acid effect $=$ Machine impact per time $\times$ machine time + added material effect Economical cost $=$ Machine cost per time $\times$ machine time + added material cost}

As other cost vectors are added, the function is growing. It is then possible to perform sensitivity analysis on the entire function. Sensitivity analysis could provide analyst with information about possible strengths, weaknesses, and relative importance of factors in the calculation. An iterative approach is preferred when performing an environmental impact analysis. Thus, it is supportive and important to do a sensitivity analysis (Emblemsvåg and Bras 1999; European Commission 2010).

The ability to track and trace the costs to environmental factors is an important feature for standard $\mathrm{ABC}$ calculations as well as for activity-based environmental impact analysis (Cohen, Venieris, and Kaimenaki 2005; Emblemsvåg 2001). The model provides information about the origins of environmental impact costs for every product (Emblemsvåg and Bras 1999). When activity-based environmental impact analysis is implemented into a DES model, the cost can be tracked down to individual units and to environmental impact sources. It is then possible to analyze the effects of individual products in a dynamic 
model. That is to analyze the impact function and trace the costs to the individual activity and individual resources.

The power of $\mathrm{ABC}$ lies in the level of details it provides. Likewise is the level of details also become its biggest criticism. It takes much resources and time to design and support an $\mathrm{ABC}$ system. However, according to Gunasekaran (1999) it is often well worth the time. When ABC models are used consistent in the organization, it is easy to add new cost objects to the existing $\mathrm{ABC}$ models (Emblemsvåg and Bras 1999). Emblemsvåg and Bras (1999) study had over 60 \% correlation in cost drivers on the unit level between economical cost and energy consumption. The study supports the conclusion that it is feasible to combine $\mathrm{ABC}$ with LCA.

The allocation of overhead costs is an important problem, which can partly be solved using a DES approach. The inability to allocate overhead costs for multi-purpose processes is a major weakness and criticism on LCA (Reap et. al. 2008). The problem could be solved by using a combination of ABC in DES and LCA. Nevertheless, there is still no formal standard method to account for and effectively allocate environmental impacts cost. To-date, the allocation task is still done on an ad-hoc manner and it is still dependent on the ability and skills of the analyst.

\subsection{Case Example}

A study on a manufacturing company was conducted to analyze implementation of ABC in DES with environmental footprint analysis. The case example is partly based on a case description that is provided by Lindskog et. al. (2011). Changes to improve the case are suggested and discussed.

\subsubsection{Case Background}

The manufacturer being studied is a supplier of machined parts to the Swedish industry with approximately 20 employers. The company has a job shop with Computer Numerical Control (CNC) machines, cutting machines, a welding station, a paint shop, and assembly stations. The company produces multiple custom made products using a functional layout. One product in the production flow was analyzed using DES software. The total impact was mainly dependent on raw material and purchased components. Hence, it is more vital in this case to improve product design and used components than to improve production processes. This example is focused on the internal processes. External outsourcing dependencies are added as static impacts to the product level.

\subsubsection{Case Result and Lessons Learned}

To limit the scope of the case, only one product was examined even though it is a multi-product site. Indirect costs from supporting functions and facility are allocated to the product level by use of the dedicated storage area for the examined product and its components compared to dedicated storage area for all products. The allocation approach gave the best representation for the actual facility usage by the product.

As output, the case example is using Global Warming Potential (GWP), which includes several types of emissions and represents them as $\mathrm{CO}_{2}$ equivalents.

The time in facility is used to allocate facility cost from product level to batch/unit level. The individual cycle time of the batch/unit through the workstations is easily modeled and tracked in a DES.

For activities in the CNC and cutting machines, the used electricity for the machines was measured in a data collection phase. Three different machine states were used: idle, busy, and down. The energy used during idling was allocated to the batch level according to the time batch was using the machine. The energy used while the machine was busy was directly allocated to the individual unit.

Auxiliary media usage for $\mathrm{CNC}$ machines was added to the unit level using machine time as allocation method. Usage of Auxiliary media per machine time was approximated in a data collection phase by total usage divided by total machine time. For manual station, welding station, and paint shop, static environmental impact method was used to account for the use of shield gas, welding rod, and paint for each 
unit. The time for welding and painting is varying and affects the energy used in the stations. A detailed study on the working method in the manual stations would definitely result in a better cost model. This would give a more accurate model that would reveal problems with time variance. Moreover, it could also show how standardized working methods could minimize environmental impact.

Wasted products are not taken into consideration in the case study. In a general case, the impact from wasted product would be put on the product level and allocated equally to the individual units.

In the case, no economic costs were analyzed. However, most of the drivers in the model would correlate to economic measurements. For an economic analysis, it would require costs data such as labor costs, marketing costs, and administration costs.

The case example indicated that DES is a viable tool for environmental analyses. The activity-based environmental cost approach fits in the DES environment. The case study was compared with a simplified LCA analysis. The LCA method comparison was used to validate the concept. The comparison result supports that the model was comparable to a LCA analysis in terms of LCA output results. Experience from the case support the fact that the DES approach takes more time to implement. However, you will get a better understanding on the sources of impact and other benefits from regular DES analyses are available within the same model.

\section{DISCUSSION}

Environmental impact calculations are complicated. There are many criticisms on the standard method LCA, which mainly origins from the subjective steps of the analysis. Many of these problems are hard to avoid. It is especially true in the inventory phase because many assumptions must be made to limit the scope of the system (Reap et al. 2008).

To make LCA analysis comparable, the same data must be used. In some cases, major differences exist in databases and in the variants of material used in the study, for example, steel. Making assumptions may affect the calculations and its outcome as well as in decision-making based on the calculations.

The ABC approach for environmental impact analysis in a DES model is a feasible method. The approach is synergistic with calculating economical costs for products. However, the method does not improve the speed of implementation for an environmental impact analysis. The analyst will still take the same amount of time and resources to collect data and perform environmental cost impact calculations. For a company that both want to use DES as a tool and at the same time need environmental footprint analyses, the merged methods has the advantage of investigating environmental effects and concurrently analyze economical and production key performance indicators (KPI).

Compared to a static LCA approach, it is possible to analyze dynamic effects in production and for new improvements of production. As new products and processes are introduced, dynamic effects that are hard to analyze using a static LCA tool can be performed with the proposed approach.

In the case example, the environmental impact for the production was low compared to the impact from the raw material. Depending on the type of product and processes, the ratio between environmental impacts of different life cycle phases can differ a lot. For electrical consumer product, the environmental impact from usage phase is usually higher than the production phase. Hence, in comparison the impacts from production will only have a minor effect on the total environmental impact. However, from a marketing point of view, it is beneficial to declare environmental footprint incurred from production. In any case, it is important to declare environmental impacts for all stages of product lifecycle, that is, raw material extraction/production, production, usage and maintenance, and recycle. The approach that has been presented helps evaluating environmental impact from the production phase, but it can theoretically be expanded to include the other phases. This presents possibilities to analyze how a product change could impact different stages of the product lifecycle. For example, a design change that makes a product more efficient to produce could increase environmental impact during the usage stage or recycle stage.

DES is a tool for highly skilled specialists. To effectively use the tool, training is required. It is difficult for an untrained person to make use of the tool. To make DES effectively used by more individuals, and therefore usable and applicable to address more situations and perform "what-if" scenarios, the tool 
must be developed with more user friendliness features and be able to accommodate more groups of users. The ABC approach could make it easier to grasp and understand, and be applied by managers with experiences other than simulation technology. The DES model does then have the opportunity to fit better and utilized more in the organization.

Dhavale (1993) stated that ABC has been used in a manufacturing environment, but it has been implemented in a wrong way. The approach could easily mislead managers because of too many details. It is therefore important that the implementation has clear goals and that the information extracted from the simulation is easy to understand and contain correct information.

One could elaborate more applications with the ABC approach. Social cost is one such application. Manual assembly may cause bad health due to repetitive nature of tasks for the workers. It is then possible to add social costs at the manual assembly station and compare and analyze the health impact when it is changed to an automatic assembly station.

\section{CONCLUSION}

There are methods developed to using ABC in a DES environment (Spedding and Sun 1999). Method also exists to use $\mathrm{ABC}$ together with environmental impact analyses (Emblemsvåg and Bras 2000). This paper discussed the strength and feasibility of an approach based on using ABC within DES for environmental impact analysis. The approach has a lower implementation cost than using LCA and DES as separate tools. It is able to help resolved the issues with allocating overhead costs. In addition, the approach helps analysts perform an unbiased evaluation of environmental impact analysis and provides reliable and robust results.

The researchers expect further challenges ahead to perform future environmental impact analysis and eco-product marking requirements with the help of a DES model. The theoretical foundation presented in this paper will be further developed and tested until 2014. Within the project EcoProIT (2011) methods and standards for using environmental impact analyses in DES will be developed. EcoProIT (2011) will facilitate a certification method on how to perform environmental impact calculation using DES. Specific, precise, reliable, and robust methods make it possible to use the approach for eco-product marking and comparison.

\section{ACKNOWLEDGEMENTS}

The researchers would like to acknowledge Swee Leong for gratefully support to the research. The funding for this research is granted by Norrahammars Mekaniska Werkstad (NMW) and ProViking through the EcoProIT project. This work has been carried out within the Sustainable Production Initiative and the Production Area of Advance at Chalmers University of Technology, which is gratefully acknowledged.

\section{REFERENCES}

Beck, U., and J.W. Nowak. 2000. "The merger of discrete event simulation with activity based costing for cost estimation in manufacturing environments." In Proceedings of the 2000 Winter Simulation Conference, edited by J. A. Joines, R. R. Barton, K. Kang and P. A. Fishwick, 2048-2054. Piscataway, New Jersey: Institute of Electrical and Electronic Engineers, Inc.

Cohen, S., G. Venieris, and E. Kaimenaki. 2005. "ABC: adopters, supporters, deniers and unawares." Managerial Auditing Journal, 20(9): 981-1000.

Dhavale, D. 1993. "Activity-Based Costing In Cellular Manufacturing Systems." Journal of Cost Management, Spring: 13-27.

EcoProIT. 2011. EcoProIT project site Acessed June 02. http://www.ecoproit.com

Emblemsvåg, J. 2001. "Activity-Based Life-Cycle Costing." Managerial Auditing Journal 16(1): 17-27.

Emblemsvåg, J., and B. Bras. 2000. Activity-Based Cost and Environmental Management - A Different Approach to the ISO 14000 Compliance. Boston: Kluwer Academic Publishers. 
Emblemsvåg, J., and B. Bras 1999. "Integrating Economic and Environmental Performance Measurements Using Activity-Based LCA." Edited by J. Jeswiet, T.N. Moore and P.H. Oosthuizen. CIRP-Proceedings, 6th international seminar on Life Cycle Engineering, 11-20. Ontario, Canada.

Ericsson, U. 2005. "Diffusion of Discrete Event Simulation in Swedish Industry." Doctorial dissertation, Department of Materials and Manufacturing Technology, Chalmers University of Technology, Gothenburg, Sweden.

European Commission - Joint Research Centre - Institute for Environment and Sustainability. 2010. International Reference Life Cycle Data System (ILCD) Handbook - General guide for Life Cycle Assessment - Detailed guidance. 1st edition. Luxembourg: Publications Office of the European Union

Gallego-Álvarez, I., J. Prado-Lorenzo, L. Rodríguez-Domínguez, and I. García-Sánchez. 2010. "Are social and environmental practices a marketing tool? Empirical evidence for the biggest European companies." Management Decision, 48(10): 1440-1455.

Gunasekaran, A. 1999. "A framework for the design and audit of an activity based costing system." Managerial Auditing Journal,14(3): 118-126.

Haanaes, K., et al. 2011. "Sustainability: The 'Embracers' Seize Advantage." MIT Sloan Management Review, 2011:Winter: 1-27.

Lindskog, E., L. Lundh, J. Berglund, Y. T. Lee, B. Johansson, and A. Skoogh 2011. "A Method for Determining the Environmental Footprint of Industrial Products Using Simulation" Accepted for Proceedings of the 2011 Winter Simulation Conference, edited by S. Jain, R. Creasey, and J. Himmespach, K. P. White Jr and M. Fu. Piscataway, New Jersey: Institute of Electrical and Electronics Engineers, Inc.

Reap, J., F. Roman, S. Duncan and B. Bras. 2008. "A survey of unresolved problems in life cycle assessment." International Journal Life Cycle Assess, 13(5): 290-300.

Russo, M. V., and P. A. Fouts. 1997. "A Resource-Based Perspective on Corporate Environmental Performance and Profitability." The Academy of Management Journal, 40(3): 534-559.

Savory, P., R. Williams, and R. Rassmuseunz. 2001. "Industrial and Management Systems Engineering." Journal of Design and Manufacturing Automation, 1(3):221-229.

Spedding, T. A., and G. Q. Sun. 1999. "Application of discrete event simulation to the activity based." International Journal of Production Economics, 58 : 289-301.

Thiede, S., C. Herrmann, and S. Kara. 2011. "State of Research and an innovative Approach for simulating Energy Flows of Manufacturing Systems." Glocalized Solutions for Sustainability in Manufacturing. Braunschweig, Germany, CIRP, 335-340.

\section{AUTHOR BIOGRAPHIES}

JON ANDERSSON is a PhD student at Chalmers University of Technology. He works mainly in the field of production simulation and especially in the project called EcoProIT (http://www.ecoproit.com). The project aims to build a industrial tool for environmental impact analysis in a powerful DES environment. His email address is Jon.Andersson@chalmers.se.

ANDERS SKOOGH is a PhD student in the field of Discrete Event Simulation at the Department of Product and Production Development, Chalmers University of Technology, Sweden. In 2005 he obtained his M.Sc. degree in Automation and Mechatronics from the same university. Anders has industrial experience of Discrete Event Simulation from his former employment as logistics developer at Volvo Car Corporation. His email address is Anders.Skoogh@chalmers.se.

BJÖRN JOHANSSON is Assistant Professor and vice head of Production Systems division at the Department of Product and Production Development, Chalmers University of Technology, Sweden. He serves as Production Modeling Corporation director for the European office in Gothenburg. His research 


\section{Andersson, Skoogh, and Johansson}

interest is in the area of discrete event simulation applied for manufacturing industries, including environmental effects modeling, modular modeling methodologies, software development, user interfaces, and input data architectures. His email address is Bjorn.Johansson@chalmers.se. 